\title{
Análise Epistemológica da Visão de Ciência dos Professores de Química e Física do Município do Rio de Janeiro*
}

\section{Renato José De Oliveira}

Escola Técnica Federal de Química do Rio de Janeiro

Discute, com base na epistemologia de Gaston Bachelard, as influências de determinadas correntes filosóficas na formação da visão de ciência dos professores de Química e Fisica, em atividade letiva no segundo grau, tomando como campo de estudo o município do Rio de Janeiro. A partir dos resultados obtidos em pesquisa realizada entre março e junho de 1990, analisa a situação do ensino secundário das referidas disciplinas, buscando apresentar alternativas para a superação do contexto adverso em que se insere a educação científica nos dias de hoje.

\section{Introdução}

Desenvolver um estudo crítico da atual situação do ensino de Química e Física no município do Rio de Janeiro é, sem dúvida, uma tarefa difícil e necessária. No que tange ao ensino das ciências físicas, muito se tem discutido sobre metodologia e psicologia da aprendizagem, bem como sobre diretrizes político-educa-cionais e seus reflexos diretos no processo educativo, do $1^{\circ}$ grau à universidade.

\footnotetext{
* $O$ artigo apresenta os resultados da pesquisa de campo realizada entre março e junho de 1990 , com vistas à elaboração da dissertação de mestrado intitulada ensino: o elo mais fraco da cadeia científica. A referida dissertação foi defendida em novembro de 1990, no Instituto de Estudos Avançados em Educação (IESAE), da Fundação Getúlio Vargas, no Rio de Janeiro, sob orientação do professor José Américo Motta Pessanha, e aprovada com louvor pela banca examinadora formada pelos professores: José Américo Motta Pessanha, Circe Navarro 'Vital Brasil e Constantino Tsallis.
} 
Sem negar a importância dos estudos desenvolvidos nessas áreas, propusemo-nos, entretanto, a conduzir nossas reflexões por um caminho ainda pouco explorado, ou seja, buscamos analisar a contextura epistemológica da Química e da Física ministradas nas escolas cariocas. A escolha do ensino de $2^{\mathrm{Q}}$ grau se deveu ao fato de, nos últimos seis anos, estarmos lecionando nesse campo de atuação profissional.

A discussão proposta nos remete invariavelmente ao contexto da filosofia da ciência, no qual várias correntes de pensamento travam polêmicas contundentes e apaixonadas. Num fórum tão diversificado quanto complexo, é naturalmente difícil participar do debate sem tomar posicionamentos claros com respeito às questões de natureza filosófica: seremos empiristas ou racionalistas, metafísicos ou antimetafísicos, continuístas ou adeptos de que o conhecimento progride através de rupturas? Tal como em tantos outros campos do saber humano, a neutralidade aqui é um mito, não cabendo avaliar posições conflitantes a partir de provas empíricas, mas pela solidez dos argumentos arrolados em defesa deste ou daquele ponto de vista. Também na filosofia da ciência, as verdades que iluminam os espíritos constroem-se a partir do embate argumentativo e não da atividade puramente demonstrativa.

Sendo nossa intenção discutir que tipo de ciência é ensinada, encontramos na epistemologia bachelardiana referenciais consistentes com os objetivos buscados. Filósofo e educador, Bachelard sempre considerou a construção do saber um empreendimento não acabado, apontando as certezas definitivas dos sábios de outrora como obstáculos ao progresso do conhecimento científico. No edifício da ciência não cabem alicerces dogmáticos; portanto, todo aquele que pretender ensiná-la deve fazer, segundo Bachelard (1977), um "voto secreto": continuar sendo, antes de tudo, estudante.

Tendo em vista a análise epistemológica proposta, podemos assinalar enquanto parâmetros fundamentais a visão de ciências do aluno, o perfil do livro didático e a visão de ciência do professor. Evidentemente tais parâmetros estão interligados, po- 
rém como a investigação do conjunto de relações é bastante complexa, optamos por centrar a pesquisa na visão de ciência do professor.

Estreitamente vinculado ao cotidiano das salas de aula, o referencial tomado como objeto de estudo permite avaliar diretamente o contexto da transmissão dos conhecimentos científicos ao aluno. O instrumento de pesquisa escolhido foi um questionário composto por questões objetivas, distribuído a professores de Química e Física do município do Rio de Janeiro, nos próprios locais de trabalho, entre março e junho de 1990.

Naturalmente esse tipo de pesquisa de campo apresenta inúmeras limitações, sobretudo por levantar dados a partir de questões de múltipla escolha, as quais nem sempre são capazes de traduzir integralmente o pensamento do indivíduo pesquisado. De todo modo, foi possível aferir tendências gerais que nos permitiram traçar um perfil do contexto epistemológico que permeia o ensino de Química e Física nas escolas secundárias cariocas.

\section{$O$ instrumento de pesquisa \\ CONSIDERAÇÕES INICIAIS}

O questionário aplicado constou de dez questões objetivas. As cinco primeiras abordaram temas relativos à atividade científica em geral. A intenção foi verificar, de acordo com o enfoque bachelardiano, as influências de determinadas correntes filosóficas na opinião do professorado acerca desses temas. Podemos, então, apontar duas vertentes genéricas: ciência tradicional e novo espírito científico (NEC).

A ciência tradicional vinculam-se a Química e a Física clássicas, influenciadas em maior ou menor extensão pelo empirismo, pelo racionalismo e pelo positivismo. Para Bachelard (1971), trata-se de uma "ciência de instrução ministerial" cujos pressupostos básicos são medir e contar, e a máxima pedagógica segue sendo "ver para compreender".

Ao novo espírito científico podemos associar a Química e a Física contemporâneas, cujo desenvolvimento se dá a partir das

R. bras. Est. pedag., Brasília, v.72, n.1 72, p.335-355, set ./dez. 1991 
rupturas epistemológicas geradas pela mecânica quântica e pela teoria da relatividade. Para o NEC, razão e experimentação devem manter estreito diálogo, pois a investigação não é mais o ato de "desvelar" segredos ocultos sob o manto dos fenômenos, mas, ao contrário, representa a própria construção da realidade feno-mênica. Como destaca Bachelard (1947), o fato observável só possui caráter científico quando associado a uma interpretação racional. Dissociado desta, converte-se em objeto de admiração, não de estudo.

Nas cinco questões subseqüentes, buscamos avaliar como o legado filosófico influencia a transmissão de conceitos básicos comuns ao ensino de Química e Física.

De acordo com Bachelard (1983), quando formaliza uma noção de base, o espírito científico sofre influências diversas. É o realismo ingênuo, ou realismo do senso comum, que primeiro norteia a formalização do conceito, conferindo às evidências imediatas o caráter de verdades absolutas. Registrada tão-somente por meio dos sentidos, a realidade se afirma tal como aparenta ser.

Num segundo momento, porém, o espírito científico tem necessidade de operacionalizar as noções constituídas. Ao realismo da aparência deve, pois, somar-se o realismo da medida, de sorte que o conceito adquire contornos empírico-instrumentais, caracterizando assim a influência do empirismo-positivismo. Mas as observações e medições por si só não satisfazem: a compreensão fracassa se o espírito não busca abstrair as relações matemáticas que fundamentam a estrutura conceitual. O racionalismo clássico (de tipo cartesiano, newtoniano ou kantiano) aparece então como filosofia capaz de conferir caráter lógico à noção anteriormente presa ao sensível e ao mensurável.

Embora represente um marco evolutivo em relação às filosofias anteriores, o racionalismo clássico torna o conceito invariavelmente prisioneiro do dogmatismo da Razão. Solidamente edificado, o corpo de verdades científicas parece querer perpetuar-se, emprestando à atividade racional certo "sabor escolar", conforme salienta Bachelard (1972). Mas a ciência só avança quando investe contra as estruturas já constituídas, o que mostra ser ne- 
cessário promover a dialetização ou o desdobramento do conceito: o simples não é um absoluto, mas apenas a primeira aproximação do complexo.

Temos aí, então, um racionalismo aberto, sempre pronto a retificar os erros, ampliando as fronteiras do saber (racionalismo discursivo, segundo a classificação bachelardiana).

Evidentemente, as influências das filosofias citadas não se dão de maneira uniforme, diferenciando-se conforme a história de vida e a formação cultural do indivíduo. Bachelard, por exemplo, destaca a grande influência do racionalismo clássico na formação de seu conceito pessoal de massa e a justifica reportando-se aos longos anos dedicados ao ensino da Mecânica na escola secundária.

$\mathrm{Na}$ impossibilidade de pedir a cada professor um histórico das influências mais marcantes sobre sua visão de ciência e sobre as noções de base tratadas, tivemos por meta averiguar genericamente as preferências docentes, considerando-as enquanto orientações epistemológicas.

Assim sendo, as opções formuladas em cada questão objetiva buscavam refletir diferentes orientações epistemológicas. Solicitamos ao professor que escolhesse, dentre as alternativas propostas, aquela que mais se aproximasse do seu ponto de vista, indicando, naturalmente, a possibilidade de ser manifestada outra opinião ou a de serem feitos comentários adicionais.

\section{QUESTÕES APRESENTADAS}

Foram apresentadas, na mesma ordem e conforme a redação abaixo, as seguintes questões:

1. O homem faz ciência quando:

a) Percebe e registra os fenômenos naturais, domina-os e lhes dá alguma forma de utilização prática.

b) Estuda a regularidade dos fenômenos, estabelece as leis que os regem e permitem seu controle e previsão.

c) Descobre gradualmente as verdades que a natureza deixou escritas na realidade que nos cerca. 
d) Não aceita a existência de verdades preestabelecidas, retificando os erros surgidos no processo de construção do saber.

Justificativa ou outro ponto de vista:

2. $\mathrm{O}$ ato de conhecer se liga principalmente:

a) A certeza de que todo conhecimento que se pode obter deriva necessariamente da experiência.

b) A certeza de que o conhecimento de um fenômeno se resume ao ato de descobrir as causas que provocam determinados efeitos.

c) Ao esforço humano em desdobrar as estruturas complexas do mundo em estruturas cada vez mais simples de serem compreendidas.

d) A verificação de que toda estrutura simples se desdo bra em estruturas de maior complexidade.

Justificativa ou outro ponto de vista:

3. Na sua opinião, toda teoria científica representa:

a) Um saber bem estabelecido, estável, difícil de ser modificado.

b) A evolução de um saber menos geral que é sempre gradualmente aperfeiçoado.

c) Um saber que se constrói à medida que se questiona constantemente.

Justificativa ou outro ponto de vista:

4. Para o pesquisador, o objeto de seu estudo representa:

a) Algo que após ser manipulado e medido experimentalmente revelará tudo o quanto pode revelar ao conhecimento.

b) Algo que contém tudo aquilo que se deseja saber e mais cedo ou mais tarde será descoberto.

c) Algo com o qual estabelece uma relação, pois o pesquisador muda seu modo de pensar quando modifica o objeto. 
Justificativa ou outro ponto de vista:

5. Podemos tomar como método científico:

a) Uma seqüência de atividades que começa na observação do fenômeno, passa à formulação de hipóteses, testa experimentalmente as hipóteses e por fim estabelece as leis.

b) Um processo no qual, partindo de uma hipótese genérica, o cientista deduz as conclusões, isto é, os enunciados gerais ou predições particulares nela baseados.

c) Um processo no qual teoria e experiência mantêm laços estreitos, pressupondo sempre formas novas e diferenciadas de abordar o objeto de estudo.

Justificativa ou outro ponto de vista:

6. Para o aluno, massa seria melhor conceituada como:

a) A quantidade de matéria contida num corpo.

b) Uma medida atribuída a cada corpo, medida esta que se obtém pela comparação do corpo com um padrão, usando-se o princípio da balança de braços iguais.

c) A propriedade de um corpo em resistir à ação de uma determinada força que lhe é aplicada.

d) Uma grandeza relativa à velocidade do corpo.

Justificativa ou outro conceito: assim:

7. Para o aluno, matéria e energia seriam melhor conceituadas

a) Matéria é tudo que ocupa lugar no espaço e energia é tudo que modifica a matéria, provoca ou anula movimentos e causa sensações.

b) Matéria é tudo que apresenta uma propriedade mensurável, a massa, e energia é tudo capaz de produzir trabalho.

c) Matéria é a essência dos materiais que formam o universo, é extensa, ao passo que energia não se define: registram-se seus efeitos. 
d) Matéria é energia, energia é matéria: ambas formam um complexo cujas propriedades se desenvolvem no espaço e no tempo.

Justificativa ou outro conceito:

8. Para o aluno, substância seria melhor conceituada como:

a) diferentes tipos de matéria que apresentam características próprias: o açúcar é doce, a água é incolor, inodora e insí-pida.

b) Toda porção de matéria capaz de guardar as mesmas propriedades físicas e químicas.

c) Diferentes qualidades de matéria, formadas por um único tipo de constituinte: átomos, moléculas ou aglomerados iô-nicos.

d) Complexos integrados de matéria e energia, cujas propriedades são definidas estatisticamente.

Justificativa ou outro conceito:

9. Para o aluno, a melhor conceituação de fenômeno seria:

a) Tudo que pode ser observado na natureza e tem causas determinadas.

b) todo acontecimento que está ligado a outro acontecimento anterior, que é sua causa imediata.

c) Tudo que pode ser compreendido racionalmente a partir da observação da realidade.

d) Tudo o que pode ser observado ou realizado por experiências racionalmente planejadas.

Justificativa ou outro conceito:

10. Para o aluno, molécula seria melhor conceituada como: 
a) A menor parte da substância capaz de guardar todas as suas propriedades.

b) Uma representação teórica que auxilia na compreensão dos fenômenos físicos e químicos sob o ponto de vista microscópico.

c) Um arranjo energeticamente estável formado pela associação de núcleos e elétrons.

Justificativa ou outro conceito:

Nome:

(Preencher se quiser)

Disciplina que leciona:

(Favor preencher)

Escola em que leciona:

(Favor preencher)

Tempo de magistério:

(Favor preencher)

Instituição pela qual se formou:

(Favor preencher)

Leciona em outra escola: S ( ) N ( )

Amostragem, metodologia e resultados da pesquisa de campo

AMOSTRAGEM

Para chegar à população-alvo fizemos a distribuição dos questionários em diferentes escolas das redes federal, estadual e particular de ensino, buscando abranger quatro grandes regiões geográficas do município (Zonas Sul, Norte, Oeste e Centro).

Com o objetivo de diversificar a distribuição, realizamos inicialmente um levantamento do número de escolas de segundo

R. bras. Est. pedag., Brasília, v.72, n.172, p.335-355, set./dez. 1991 
grau em atividade no ano de 1990, no município do Rio de Janeiro ${ }^{1}$. No que tange às redes federal e estadual, cujo número de escolas é menor, obtivemos valores atualizados (110 estabelecimentos). Com respeito à rede particular, trabalhamos com dados relativos a fevereiro de 1989, obtidos junto ao Conselho Estadual de Educação em abril de 1990 (409 estabelecimentos).

Buscamos, então, fazer a entrega dos questionários tendo como referência o quadro escolar do município. As tabelas 1 e 2 produzem o contexto da amostragem:

Tabela 1 - Distribuição percentual de questionários por região geográfica

\begin{tabular}{|c|c|}
\hline Região Geográfica & $\mathbf{1}$ \\
\hline Centro & 9,05 \\
\hline Zona Oeste & 19,30 \\
\hline Zona Sul & 24,00 \\
\hline Zona Norte & 47,10 \\
\hline
\end{tabular}

Tabela 2 - Distribuição percentual de questionários por rede de ensino

\begin{tabular}{|c|c|}
\hline Rede de Ensino & \% do total distribuído \\
\hline Federal & 17,5 \\
\hline Estadual & 37,8 \\
\hline Particular & 44,7 \\
\hline
\end{tabular}

Obs.: foram visitadas 74 escolas.

1 Consideramos apenas os estabelecimentos que ministram ensino regular de segundo grau (três séries letivas), pois o ensino supletivo constitui, por suas próprias características, um campo à parte de investigação. 
Embora tenha sido o parâmetro norteador da entrega dos questionários, o mapeamento da rede escolar não pode ser tomado apriori como garantia de distribuição eqüitativa. A grande maioria dos professores constitui uma massa flutuante, que leciona em mais de um estabelecimento de ensino (inclusive em mais de uma rede) e em localidades diversas. Tal característica, aliás, dificultou extremamente a quantificação do número de docentes em atividade. Deste modo, tivemos que estimar o número de vagas preenchidas nas três redes, chegando, então, a um total de $3.006^{\wedge}$. Na medida em que o número de vagas preenchidas é muito superior ao número real de professores em atividade letiva, introduzimos um fator de redução para estimar o total buscado. Admitindo que a maioria dos docentes não leciona em apenas um estabelecimento, tomamos o valor dois como fator médio de redução ${ }^{1}$. Assim, chegamos finalmente ao total aproximado de profissionais em atividade no município do Rio de janeiro entre os meses de março e junho de 1990 (1.503 professores).

Com base nesse cálculo, distribuímos 508 questionários (33,9\% da população-alvo estimada) e obtivemos um retorno de $152(10,1 \%)$.

\section{METODOLOGIA E RESULTADOS}

Dos 152 questionários recebidos, 55 corresponderam a professores de Física, 85 a professores de Química e 12 foram re-

\footnotetext{
2 Com relação a rede federal, dado o pequeno número de escolas, obtivemos com facilidade o total de vagas preenchidas (200). Na rede estadual, a partir de dados levantados junto aos núcleos de segundo grau, obtivemos um total relativo a $80 \%$ do número de escolas. Mantendo a mesma proporcionalidade, estimamos o total de vagas preenchidas (070) Na rede particular só foi possível obter dados relativos a $13.2 \%$ do total de escolas. Com base na razão número de vagas/escola verificada, estimamos o número de vagas preenchidas (2.130).

3 Tomando por base as informações prestadas em 133 questionários, constatamos que a grande maioria do professorado (70\%) leciona em mais de uma escola, o que, de fato, torna válida a adoção do fator de redução mencionado.
} 
jeitados por não se enquadrarem nas mesmas condições dos demais ${ }^{4}$.

O predomínio dos professores de Química na amostragem poderia sugerir, em primeira instância, maior receptividade destes com relação à pesquisa. Contudo, é preciso frisar que a composição da população-alvo não é homogênea, pois em várias escolas das três redes de ensino constatamos maior carência de professores de Física.

Separamos então os questionários de acordo com a disciplina lecionada, visando aferir semelhanças e diferenças. Para cada um dos temas tratados, obtivemos os resultados indicados na tabela 3.

\section{Análise dos resultados}

Podemos verificar que em nove dos dez temas tratados houve convergência de opinião entre os professores de Física e os de Química, indicando que, de fato, as orientações epistemológicas constituem padrões culturais típicos, estando geralmente ligadas ao que se pode chamar de senso comum científico ${ }^{5}$.

Adotando, a exemplo de Bachelard, um sentido preferencial para a evolução de conhecimento científico, discutiremos as

\footnotetext{
4 Na composição da fração rejeitada incluem-se os seguintes casos:

. cinco questionários, respondidos por professores de Química, da Fundação Técnica

Educacional Souza Marques (instituição de terceiro grau), nao mencionavam se o docente leciona ou não no segundo grau.

. cinco questionários, respondidos por professores de Física do Colégio Pedro II (unidade Centro), apresentavam as fichas de dados pessoais preenchidas com a mesma letra, além de marcações padronizadas nas diferentes questões.

dois questionários recebidos pelo correio não faziam qualquer referência à disciplina ministrada pelo docente (ficha de dados pessoais em branco).
}

6 Bachelard (1983) assinala que o pensamento científico ainda se acha majoritariamente preso a estágios filosóficos menos avançados. $O$ racionalismo discursivo tem portanto, contra si, fatores de peso, como por exemplo o senso comum, o conhecimento imediato, a técnica industrial, entre outros. Tais fatores contribuem para formar uma mentalidade ou um consenso bem estabelecido, o qual chamamos de senso comum científico. 
Tabela 3 - Resultados obtidos na pesquisa de campo

\begin{tabular}{|c|c|c|c|c|}
\hline Tema & Orientação & Opção & \multicolumn{2}{|c|}{ Percentual } \\
\hline & & & $\mathrm{PF}$ & $\overline{P Q}$ \\
\hline $\begin{array}{l}\text { Atividade } \\
\text { científica }\end{array}$ & Positivismo & B & 66 & 49 \\
\hline $\begin{array}{l}\text { Natureza do } \\
\text { conhecimento }\end{array}$ & $\begin{array}{l}\text { Racionalismo } \\
\text { Clássico }\end{array}$ & $\mathrm{C}$ & 58 & 56 \\
\hline $\begin{array}{l}\text { Teorias } \\
\text { científicas }\end{array}$ & $\begin{array}{l}\text { Racionalismo } \\
\text { Discursivo }\end{array}$ & $\mathrm{C}$ & 71 & 63 \\
\hline $\begin{array}{c}\text { Relação } \\
\text { Sujeito/Objeto }\end{array}$ & $\begin{array}{l}\text { Racionalismo } \\
\text { Discursivo }\end{array}$ & c & 58 & 51 \\
\hline $\begin{array}{c}\text { Método } \\
\text { científico }\end{array}$ & Positivismo & A & 60 & 63 \\
\hline $\begin{array}{l}\text { Conceito de } \\
\text { massa }\end{array}$ & $\begin{array}{l}\text { Realismo } \\
\text { Ingênuo }\end{array}$ & A & 40 & 45 \\
\hline $\begin{array}{l}\text { Conceitos } \\
\text { de matéria e } \\
\text { energia }\end{array}$ & \begin{tabular}{l}
\multicolumn{1}{c}{ Realismo } \\
Ingênuo (PQ) \\
Racionalismo \\
Discursivo(PF)
\end{tabular} & $\begin{array}{l}\text { A } \\
\text { D }\end{array}$ & 31 & 45 \\
\hline $\begin{array}{l}\text { Conceito de } \\
\text { substância }\end{array}$ & Empirismo & A & 36 & 33 \\
\hline $\begin{array}{l}\text { Conceito de } \\
\text { Fenômeno }\end{array}$ & $\begin{array}{l}\text { Realismo } \\
\text { Ingênuo }\end{array}$ & A & 57 & 40 \\
\hline $\begin{array}{l}\text { Conceito de } \\
\text { molécula }\end{array}$ & $\begin{array}{l}\text { Realismo } \\
\text { Ingênuo }\end{array}$ & A & 73 & 51 \\
\hline
\end{tabular}

influências observadas segundo um eixo epistêmico. Esse eixo tem por origem o Realismo Ingênuo, o qual representa o estágio menos evoluído da constituição dos conceitos. A ele seguem-se o Em-pirismoPositivismo, o Racionalismo Clássico e, por fim, o Racionalismo Discursivo.

B. bras. Est. pedag., Brasília, v.72, n.172, p.335-355, set./dez. 1991 
O realismo ingênuo predomina na constituição dos conceitos de massa, fenômeno, molécula e ainda nos de matéria e energia (professores de Química).

No que se refere ao conceito de massa, a preferência recaiu sobre a associação imediata com a quantidade de matéria contida nos corpos. Tal definição é facilmente assimilável, porque se acha diretamente ligada ao conhecimento comum. Trata-se de considerar a massa enquanto propriedade que precisa ser apenas reconhecida pelo aluno e não necessariamente compreendida. Por essa razão, ela é definida enquanto expressão da quantidade de matéria existente, enquanto da própria matéria diz-se que tem massa e ocupa lugar no espaço... Como tão-somente o reconhecimento (feito a partir de critérios visuais e tácteis) é buscado, o professor não atenta para a redundância que as definições de massa e de matéria assim formuladas dão lugar.

Por outro lado, é preciso destacar que a comodidade inicial trazida pelo realismo ingênuo logo esbarra em sérios problemas. Modernamente, a União Internacional de Química Pura e Aplicada (IUPAC) adota o termo "amount of substance" - cuja versão oficial brasileira é justamente "quantidade de matéria" - para designar uma grandeza diversa da massa. A quantidade de matéria representa a quantidade de entidades elementares (átomos, moléculas, íons, elétrons etc.) presentes em determinada porção de substância.

Já para a noção de fenômeno, o realismo ingênuo tem o grave inconveniente de manter o pensamento restrito à idéia de acontecimento natural observável, cujas causas se acham previamente estabelecidas. Sob esse referencial, $\mathrm{o}$ mundo se coloca perante o aprendiz enquanto espetáculo oferecido à contemplação, quando paradoxalmente a Química e a Física modernas trabalham essencialmente no domínio daquilo que não se vê. A realidade fenomênica adquire cada vez mais o caráter de objeto construído a partir da técnica investigativa, a qual, por sua vez, é fruto da aplicação de raciocínios que vão muito além do que a visão pode registrar.

$\mathrm{Na}$ Veiculação do conceito de molécula, o realismo ingênuo apóia-se na obviedade do princípio da divisão: para pas- 
sar do macro ao micromundo, da substância à molécula, basta simplesmente fracionar. Deste modo, o que se acha presente no grande estará necessariamente presente no pequeno, ou seja, as propriedades são encaradas como atributos inalienáveis da substância, não importando a porção tomada como referência. Assim, a molécula é grosseiramente reduzida à condição de grão substancial, ou, conforme comentou um professor em seu questionário, "ela seria o menor pedaço que se poderia extrair" (apud Oliveira, 1990).

Se num primeiro momento a simplicidade desse tipo de conceituação parece clarear os horizontes do estudante, na seqüência da aprendizagem obscurece inevitavelmente sua compreensão. Características macroscópicas da água, como por exemplo a propriedade de ser líquida num largo intervalo de temperatura à pressão ambiente, não dizem respeito à molécula individualmente. Ao contrário, só se manifestam a partir de interações entre moléculas.

A orientação empírieo-positivista predomina nas concepções de substância, atividade e método científico. Um procedimento didático comumente utilizado pelos professores é caracterizar as substâncias inicialmente através de propriedades físicas e químicas. Esse critério empírico representa, sem dúvida, um marco evolutivo em relação ao realismo ingênuo, que caracteriza a substância por meio de propriedades sensíveis (odor, sabor, cor etc), as quais, como já destacara Descartes ${ }^{\prime 1}$, são essencialmente efêmeras.

No entanto, ater-se ao empirismo não implica garantir a compreensão. Afinal, substâncias como o carbono podem apresentar propriedades inteiramente distintas (caso do grafite e do diamante), dependendo do tipo de agregação dos constituintes. Não

O Nas Meditações Metafísicas, Descartes observa que quando é aproximado do fogo, um pedaço de cera perde invariavelmente os atributos sensíveis (doçura, perfume, cor etc). No entanto, o eu pensante nao deixa de reconhecer na massa derretida a qualidade de ser cera, denotando assim que a compreensão do objeto nao se funda no depoimento imediato dos sentidos, os quais podem ser muitas vezes enganosos. 
é possível, portanto, explicar a propriedade substancial sem desenvolver um estudo estrutural consistente. A racionalização deve, pois, abrandar o absolutismo da evidência empírica, retirando da noção o caráter estritamente pragmático.

Sendo capaz de fornecer esquemas lógicos fáceis de serem aceitos, o positivismo domina amplamente as concepções de atividade e de método científico. Embora a ciência de ponta não se prenda a esquemas rígidos de pesquisa e tenha sempre ao seu dispor diversos métodos investigativos, para o senso comum prevalece a visão de que o trabalho científico se resume a um plano de ação unitário. Assim estabelecer leis, prever e controlar fenômenos exigem a criteriosa obediência ao método (universal), o qual permite ao cientista desvelar a regularidade presente no cosmo. Para Comte (1978), a permanência do método se constituía em fator indispensável ao progresso científico, já que a inteligência humana é "antipática a toda mudança brusca" (p.46).

Mas são justamente as mudanças bruscas ou rupturas que caracterizam a evolução do pensamento. Assim, quando antigos pressupostos caem por terra, levando consigo toda uma visão de mundo obsoleta, a metodologia não pode permanecer intocável. São precisos novos métodos, ditados pela própria dinâmica da investigação. Por conseguinte, como frisa Bachelard (1972), "o método está sempre em discussão", não devendo nunca se transformar em receituário inquestionável, sob pena de bloquear irreversivelmente o avanço do saber.

Seguindo o eixo epistêmico traçado, ingressamos agora no campo do racionalismo. Sem dúvida, aqui, as dicussões se colocam acima das impressões sensíveis, do pragmatismo, das evidências imediatas. E a Razão, não o olhar, que estabelece as regras do jogo. Mas que regras serão essas, flexíveis ou fixas? Que tipo de jogo estará em curso: o do conhecimento dialético ou o do conhecimento dogmático?

Quando se trata de falar sobre a natureza do conhecimento, o racionalismo clássico tende a predominar, sobretudo por estar de acordo com as premissas do senso comum. É profundamente tranqüilizador para o espírito acreditar que as estruturas 
complexas do mundo são sempre redutíveis a estruturas mais simples, cuja compreensão é o primeiro grande passo na caminhada do saber humano.

A noção de que o complexo não é alcançado pela justaposição de simplicidades, as quais são apenas verdades de primeira aproximação, é bastante estranha ao senso comum. Normalmente habituada a lidar com a comodidade gerada pelo absoluto, a Razão tende a se fixar nas estruturas simples sem se dar conta de que estas constituem tão-somente crenças filosóficas. Nenhuma estrutura é simples por si mesma e sim porque estabelecemos um consenso acerca de sua natureza. Se o consenso é rompido, a simplicidade naturalmente se esfuma. Nesse ponto, a Razão se agita, entra em crise e por fim avança, pois segundo Bachelard (1972), somente as crises podem efetivamente instruí-la.

Nas questões relativas à natureza das teorias científicas, da relação entre o pesquisador (sujeito) e o objeto de estudo e a conceituação de matéria e energia (professores de Física), a pesquisa apontou o predomínio do racionalismo discursivo. Sem dúvida, ao colocarem em xeque princípios bem estabelecidos da Física clássica, o relativismo einsteiniano e a mecânica quântica influenciaram decisivamente $o$ pensamento científico do século XX. Mesmo que o significado filosófico mais profundo dessas rupturas ainda não seja familiar ao senso comum, é atualmente impossível conferir às teorias científicas o estatuto de saber estável, não sujeito a questionamentos. Claro exemplo disso encontramos em Máximo e Alvarenga (1976), que no primeiro capítulo de um de seus livros didáticos de Física comentam:

Os físicos têm de estar alerta e o constante reexame de velhos e bem estabelecidos conceitos conduz, muitas vezes, a consideráveis alterações. Algumas vezes, estas alterações são tão chocantes e tão contrárias ao senso comum, que elas custam a ser aceitas, constituindo surpresa para os próprios físicos.

Quanto à relação sujeito-objeto, a predominância do racionalismo discursivo leva a algumas reflexões em especial. E pos- 
sível que alguma comparação com as ciências sociais — para as quais é fundamental considerar as interações entre pesquisadores e pesquisados - tenha sido estabelecida. O comentário abaixo, feito por um professor de Física, revela-nos indícios disso:

O pesquisador também faz parte do mundo, logo ele também deve ser inserido no objeto a ser conhecido, (apud Oliveira, 1990)

No campo das ciências físicas, as interações são, no entanto, de natureza diversa, posto que não se trata da relação entre indivíduos, mas da relação entre a comunidade científica e os fenômenos investigados. A mudança do modo de pensar conforme o curso da investigação caracteriza a presença de uma razão aberta, a qual, como bem sublinha Bachelard (1972), não teme arriscar as certezas anteriores adquiridas quando se dispõe a conduzir determinada pesquisa. Essa linha de ação do racionalismo discursivo contrasta com as filosofias precedentes, que não consideram o conhecimento científico um processo construtivo, mas sim a revelação de verdades universais previamente estabelecidas.

Levando em conta o amplo predomínio das filosofias realistas, com respeito aos demais temas tratados, a preponderância do racionalismo discursivo, no que tange à relação sujeito-objeto, merece investigação mais criteriosa, de forma que se possa aferir com maior segurança as reais dimensões da tendência revelada por nossa pesquisa.

\section{Conclusões}

Os resultados obtidos nos indicaram o quanto as conceituações ligadas à ciência tradicional (sobretudo ao campo realista) norteiam o trabalho docente. Por serem típicas do senso comum, as filosofias realistas pertencem também à bagagem cultural do aluno, não podendo, portanto, ser ignoradas pelos professores. A perspectiva não deve ser "zerar intelectualmente o aprendiz", mas ter como estratégia pedagógica levá-lo a superar as fortes convicções oriundas do conhecimento aparente do real. 
Se queremos efetivamente ensinar ciência, temos que ensinar o estudante a pensar de forma diferente. Não se trata de encaixar a realidade no arcabouço limitado do conhecimento comum, pois não é a ciência que precisa adaptar-se ao aprendiz. Ao contrário, este é quem deverá se desenvolver para dela se apropriar devidamente. Ao educador cabe a fascinante tarefa de fornecer aos jovens espíritos os instrumentos capazes de consolidar tal apropriação. E cabe fazê-lo não de forma dogmática ou impositiva. As aulas de Química e Física jamais podem ser transformadas em atividades monologadas, nas quais o professor expõe as verdades e os alunos aquiescem passivamente.

É justamente quando manifesta as perplexidades, as dúvidas, e mesmo o desconforto frente às novidades debatidas, que o estudante está de fato se educando. Afinal, não é sem algum pesar que se abandona a comodidade propiciada pelas evidências do senso comum. Entretanto, ao adotar um discurso imposto, mesmo tendo como perspectiva passar com correção os conteúdos, o professor não logrará êxito algum. É preciso aprender com o aluno, buscando antes de tudo compreender as razões da sua incompreensão.

Se as aulas de Química e Física se tornarem espaços abertos ao diálogo - contrariando o tabu de que na atividade científica não há lugar para a argumentação, mas tão-somente para as demonstrações objetivas , estaremos caminhando no sentido de romper com o marasmo instalado no ensino secundário de ciências. Só assim será possível dar um salto de qualidade, substituindo a prática mnemônica e repetidora pelo raciocínio crítico, fundamental para o sucesso de todo e qualquer processo educativo.

\section{Referências bibliográficas}

BACHELARD, Gaston. La formation de l'esprit scientifique. Paris: J. Vrin, 1947.

BACHELARD, Études. Paris: J. Vrin, 1971. 
BACHELARD, Lengagement rationaliste. Paris: Presses Universitaires de France, 1972.

BACHELARD, O racionalismo aplicado. Rio de Janeiro: Zahar, 1977.

BACHELARD, La philosophie du non. Paris: Presses Universitaires de France, 1983.

COMTE, Auguste. Discurso sobre o espírito positivo. São Paulo: Abril, 1978. p.43-94.

DESCARTES, René. Meditações metafísicas. Rio de Janeiro: Mandarino \& Molinari, [19--].

MÁXIMO, Antonio, ALVARENGA, Beatriz. Física. Belo Horizonte: Bernardo Alvarez, 1976.

OLrVEIRA, Renato José de. Ensino: o elo mais fraco da cadeia científica. Rio de Janeiro, 1990. 241p. Dissertação (Mestrado em Educação) - Instituto de Estudos Avançados em Educação, Fundação Getúlio Vargas.

Recebido em 27 de junho de 1991

Renato José de Oliveira, mestre em Educação pelo IESAE, da Fundação Getúlio Vargas, é professor da Escola Técnica Federal de Química do Rio de Janeiro.

Based on Gaston Bachelards epistemology, we discuss in this article the influence of certain philosophical currents in the formation of Scientific views of a group of highschool teachers of Chemistry and Physics presently Working in the city of Rio de Janeiro. From the results of a research conducted between March and June 1990, we have analyzed the teaching status of mentioned disciplines, aiming to suggest alternatives to overcome the highly adverse conditions in which the teaching of science in highschool is immerse today.

Dans cet article nous avons traité - en suivant lepistemologie de Gaston bachelard - le role joué pai- les philosophies qui ont influencé 
Ia formation de là pensée scientifique des professeurs de Chimie et Physique qui enseignent à Rio de Janeiro. A partir des résultats d'une enquete realisé parmi Mars et Juin 1990, nous avons pu analyser là situation de l'enseignement de Chimie et Physique au deuxième cycle, et proposer, à là suite, des alternatives pour changer le tableau négatif qui caracterise Léducation scientifique aujourd'hui.

Este artículo discute - con base en là epistemologia de Gaston Bachelard - Ias influencias de algunas filosofias en là formación del pensamiento cientifico de los profesores de Química y Fisica que traba-jan en Rio de Janeiro. Partiendo de los resultados de una investigación realizada en el periodo de marzo ajunio de 1990, analizamos là situación de Ia ensenanza de Química y Física en là escuela de nível médio, proponiendo alternativas para cambiar el cuadro negativo que envuelve là educación científica hoy.

R. bras. Est. pedag., Brasília, v.72, n.172, p.335-356, set./dez. 1991 